\title{
Coupling between the lower and middle atmosphere observed during a very severe cyclonic storm 'Madi'
}

\author{
H. Himabindu(1), M. Venkat Ratnam ${ }^{\left(1^{*}\right)}$, V. Yesubabu(1), C.V. Naidu(2), S. Vijaya Bhaskara Rao(3) \\ National Atmospheric Research Laboratory (NARL), Gadanki - 517 112, India \\ *vratnam@narl.gov.in ; himabindhu@narl.gov.in
}

Synoptic scale systems like cyclones can generate variety of the waves which propagate from its source to the upper atmosphere. Coupling between the lower and upper atmosphere over Gadanki $\left(13.5^{\circ} \mathrm{N}, 79.2^{\circ} \mathrm{E}\right)$ is observed during a very severe cyclonic storm 'Madi' (06-13 December 2013) using Weather Research and Forecast (WRF) model assimilations and simultaneous meteor radar observations from Tirupati $\left(13.6^{\circ} \mathrm{N}, 79.4^{\circ} \mathrm{E}\right)$. Since high temporal and spatial measurements are difficult to obtain during these disturbances, WRF model simulations are obtained while assimilating conventional and satellite observations using 3Dimensional variational (3DVAR) technique. The obtained outputs are checked for their consistency in predicting cyclone track and by verifying them with independent observations. The observed track of the cyclone well matched with the WRF simulations. Good match is also observed in the horizontal winds and temperature profiles with the independent Gadanki radiosonde observations and COSMIC GPS RO measurements. This close match of the assimilated outputs with the independent observations prompted us to use it to investigate the gravity waves (GWs) and tides over Gadanki/Tirupati latitude during the cyclone. GWs with the periods $1-5 \mathrm{~h}$ is observed with clear downward phase propagation. These upward propagating waves obtained from the model are again noticed in the meteor radar horizontal wind observations in the MLT region $(70-110 \mathrm{~km})$. Interestingly, enhancement in the tidal activity in both the zonal and meridional components in the MLT region is noticed during the peak cyclonic activity except the suppression of semidiurnal tide in meridional component. A very good agreement in the tidal activity is also observed in the horizontal wind components in the troposphere and lower stratosphere from the WRF model outputs. These results thus provide strong evidence on the vertical coupling of lower and upper atmosphere induced by the tropical cyclone. 